\title{
Perceived Risk of HIV Infection and Associated Factors among Secondary School Students in Wakiso District, Uganda
}

\author{
Charles Peter Osingada, ${ }^{1}$ Caroline Nabasirye, ${ }^{2}$ Sara Groves, ${ }^{3}$ and Tom Denis Ngabirano ${ }^{1}$ \\ ${ }^{1}$ Department of Nursing, School of Health Sciences, Makerere University College of Health Sciences, P.O. Box 7072, Kampala, Uganda \\ ${ }^{2}$ Mulago Hospital, P.O. Box 7051, Kampala, Uganda \\ ${ }^{3}$ Department of Nursing, Faculty of Medicine, Mbarara University of Science and Technology, P.O. Box 1410, Mbarara, Uganda
}

Correspondence should be addressed to Charles Peter Osingada; ocpeter@chs.mak.ac.ug

Received 1 December 2015; Revised 24 February 2016; Accepted 16 March 2016

Academic Editor: Carol J. Burns

Copyright (C) 2016 Charles Peter Osingada et al. This is an open access article distributed under the Creative Commons Attribution License, which permits unrestricted use, distribution, and reproduction in any medium, provided the original work is properly cited.

\begin{abstract}
Introduction. HIV/AIDS remain a major public health problem in Uganda and 4\% of individuals aged between 15 and 24 years are living with HIV. Few studies have examined HIV risk perception among adolescents in Uganda. Methods. We conducted a cross-sectional study among 379 secondary school students using multistage sampling techniques. Data were collected using an interviewer-administered questionnaire. Descriptive and logistic regression analyses were conducted. Results. One hundred ninetyone (49.6\%) of the respondents perceived themselves to be at risk of contracting HIV, 174 (45.9\%) had ever had sex, and 139 (80.4\%) had first sexual encounter at 16 years or less. Only $49 \%$ of respondents who had sex within 12 months used a condom. Being older than 17 years, knowing someone who died of HIV, early sexual debut, and having ever had sex were associated with perceived risk of contracting HIV. After multivariate analysis, knowledge of someone who died of HIV (Adjusted Odds Ratio (AOR) 16, 95\% CI 1.49-171.97) remained statistically significant. Conclusion. Many secondary school students perceived themselves to be at risk of contracting HIV; this perception is associated with knowing someone who died of HIV/AIDS. There is a need to strengthen HIV risk reduction interventions in Wakiso secondary schools.
\end{abstract}

\section{Introduction}

Worldwide, about 35.3 million people are living with HIV and AIDS and the vast majority of these are in Sub-Saharan Africa [1]. In Uganda, about $7.3 \%$ of individuals aged $15-49$ years are HIV positive and, of these, about $4 \%$ are young people aged between 15 and 24 years [2].

Given that Uganda's population is predominately composed of young people, a prevalence of $4 \%$ among individuals aged between 15 and 24 years represents a significant problem.

An individual's perception of the risk of acquiring HIV is a critical determinant of sexual behavior [3]. A few local studies have documented risk perception among adult populations in Uganda. For example, Kengeya-Kayondo and colleagues found that about $51 \%$ of adults in southwestern Uganda considered themselves to be at risk of HIV infection [4]. Specifically among Ugandan adolescents and young people, very few studies have been conducted in regard to HIV risk perception [5]. Kibombo and colleagues analyzed data from a 2004 national adolescent survey and found that most female adolescents feel at risk of HIV infection [6]. Efforts to address the challenge of HIV among young people should be based on a good understanding of HIV risk perception in this age group. In a national Aids Indicator Survey (AIS) of 2011, it was documented that unhealthy behaviors and attitudes continue to persist within the Ugandan general population. For example, the proportion of individuals who say that HIV can be prevented by using a condom and by limiting sexual intercourse to one uninfected partner was lowest among women and men aged 15-19 years [7]. In the same survey, the central region of Uganda, which includes Wakiso district, had the highest HIV prevalence rate of $10.6 \%$. Specifically among young people aged between 15 and 24 years in the central region, $6.3 \%$ of them were living with HIV. This high prevalence of HIV especially among young people, coupled with scarcity of studies focusing on HIV risk 
perception among young people in Uganda generally and in Wakiso district specifically, provided impetus for conception of this study. Therefore, the purpose of the data generated will be to address the spread of HIV infection through target interventions based upon the perception of risk.

\section{Methods}

2.1. Study Design and Setting. A cross-sectional study was conducted between February and April 2013 among secondary school students from two schools in Wakiso Town Council which is within Wakiso district. Wakiso district is located in the central region of Uganda and it covers an area of 2,807.7 square kilometers. The district has over 139 secondary schools; some are government supported and others are privately owned and supported. Wakiso Town Council has one government supported secondary school and this was purposively selected to be included in the study. The nongovernment aided school included in the study was selected by simple random sampling from a list of nongovernment aided schools in the town council. Students in ordinary and advanced levels of education were included in the study. Proportionate and systematic random samplings were used to recruit participants.

2.2. Sample Size Determination. Since the total number of students in the selected schools was big, four thousand three hundred and eighty-three, we decided to draw a sample from which findings can be generalized to the entire population of students in these two schools. The sample size was estimated using the formula $N=z^{2} p q / d^{2}$, where $N$ was the required sample size and $z$ is the value corresponding to $95 \%$ confidence level and was taken to be 1.96 . The proportion of adolescents who perceive themselves to be at risk of HIV infection in Uganda was estimated to be $55 \%$ [6]; $q$ is equivalent to $1-p$ which is 0.45 . The degree of error $(d)$ the researchers were willing to allow was $5 \%$. When substitutions were made, the final sample size for the study was 380 students.

2.3. Participants Recruitment. Participants for the study were drawn from two secondary schools in Wakiso Town Council. After obtaining permission from the district authorities, the research team then approached the leadership of each school to seek for permission to conduct the study. Proportionate sampling was used to determine a representative number of students to be interviewed in each secondary school and class. In order to give each student an equal chance to participate in the study, systematic random sampling was used to identify students to be interviewed in each class. The sampling interval in each class was determined based on the number of students in each class and the number of students to be interviewed per class. Simple random sampling was used to determine the beginning point from the class lists. In the event that the identified student was not in class at the time of data collection the next person on the list was selected and then the sampling interval was continued. This process was repeated in all the selected schools until the calculated sample size was

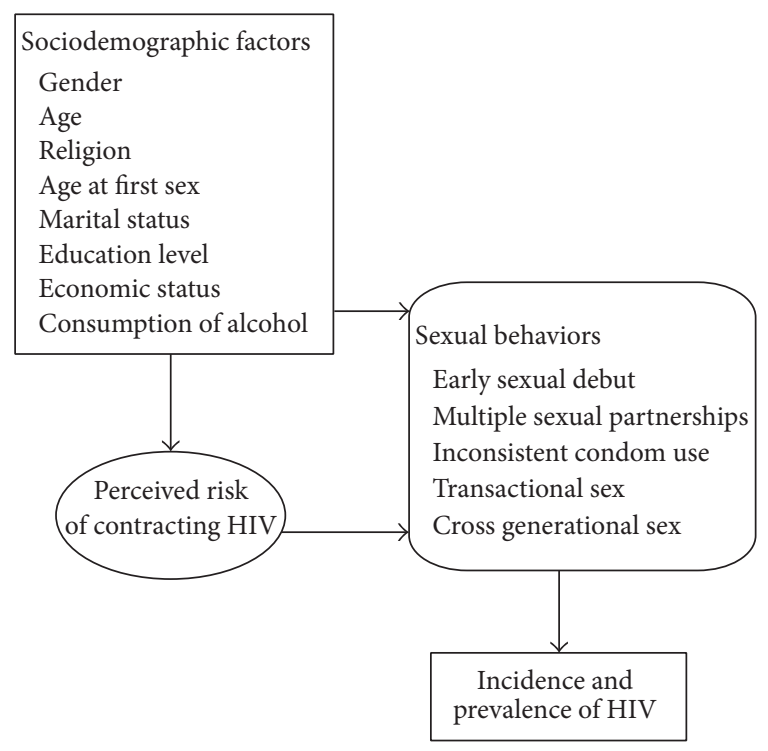

Figure 1: Conceptual framework.

attained. The interviews were conducted by the research team using a structured interviewer-administered questionnaire. The tool was developed by the investigators after a review of the literature about perceived risk for contracting HIV among adolescents. The questionnaire was written in simple English and was not translated since English is the language of instruction in the schools. The questionnaire was pretested among 38 students in another school not selected for data collection. Necessary adjustments were made to the questions to ensure clarity. The items on the questionnaire were organized under the sections of demographic characteristics, risk perception, and sexual behaviors (Figure 1). Perceived risk of contracting HIV was assessed by a single item, "Do you perceive yourself to be at risk of contracting HIV?" Responses were recorded as "yes" or "no."

2.4. Data Analysis. Data were entered into the computer using Epi info version 3.5.1 and analyzed using STATA version 10. Descriptive statistics were used to summarize the sociodemographic characteristics of participants. Bivariate and multivariate analyses were conducted to determine factors that influenced HIV risk perception. All variables which were significant at bivariate level and thought to be theoretically important in influencing the outcome variable were included in a logistic regression model. In all statistical tests a $P$ value of less than 0.05 was considered to be significant. One questionnaire was excluded at analysis stage due to incomplete entries because the student did not respond to many important questions.

\section{Results}

A total of 380 students were interviewed using intervieweradministered questionnaires, but one questionnaire was excluded from analysis. The age range was 14 to 25 years and the mean age was 17.09 ( $\mathrm{SD} \pm 1.8)$. One hundred seventy-nine 
TABLE 1: Sociodemographic characteristics of study participants.

\begin{tabular}{lcc}
\hline Variable & Frequency $(N=379)$ & Percentage \\
\hline Gender & 179 & 47.2 \\
Male & 200 & 52.8 \\
Female & & \\
Age & 260 & 68.6 \\
$\leq 17$ & 119 & 31.4 \\
$>17$ & & \\
Tribe & 217 & 57.3 \\
Baganda & 44 & 11.6 \\
Banyankole & 16 & 4.2 \\
Basoga & 102 & 26.9 \\
Others & \\
Religion & & \\
Catholic & 153 & 40.4 \\
Protestant & 101 & 26.6 \\
Muslim & 64 & 16.9 \\
Pentecostal & 49 & 12.9 \\
Others & & 3.2 \\
Level of education & 12 & 80.0 \\
Ordinary level & & 20.0 \\
Advanced level & 303 &
\end{tabular}

Others ${ }^{1}$ stands for other tribes like Batooro, Bagisu, Bafumbira, Banyoro, Musamya, Mukiga, Japadhola, Mugwere, Mudama, Acholi, and Langi. Others $^{2}$ stands for religions like SDA, orthodox, and Jehovah's Witnesses.

(47\%) of the students were male and 200 (53\%) were female. The majority were Christians and 64 (16.9\%) were Muslims. Other sociodemographic characteristics are shown in Table 1.

3.1. HIV Risk Perception and Associated Factors. One hundred ninety-one $(49.6 \%)$ of the respondents perceived themselves to be at risk of contracting HIV. From unadjusted analysis in Table 2, being female (Crude Odds Ratio (COR) 0.52, 95\% Confidence Interval (CI) 0.35-0.79) and not having taken an HIV test (COR 0.51, 95\% CI 0.33-0.78) were negatively associated with perceived risk of contracting HIV. However, being older than 17 years (COR 1.9, 95\% CI 1.222.96), having known a person who has died of HIV (COR 2.16, 95\% CI 1.30-3.58), early sexual debut (COR 2.26, 95\% CI 1.22-4.19), and having ever had sex (COR 1.88, 95\% CI 1.25-2.83) were all positively associated with perceived risk of contracting HIV. At multivariable analysis, only knowledge of someone who has died of HIV (AOR 16, 95\% CI 1.49-171.97) remained statistically significant.

3.2. Sexual Behaviors of Secondary School Students. As indicated in Table 3, of the 379 students interviewed, 174 (45.9\%) had ever had sex and slightly over $80 \%$ of them had their first sexual encounter when they were 16 years or less. Of those who had ever had sex, $60 \%$ had it within 12 months prior to the date of the interview, and $51 \%$ of them did not use a condom. Fifty-six percent of the adolescents had ever had more than one sexual partner and, of those who had ever had sex, 52.5\% did it after drinking alcohol. See details in Table 3.

\section{Discussion}

4.1. Perceived Risk of Contracting HIV. Studies of HIV risk perception among adolescents in Uganda are very few even though about $56.1 \%$ of the population comprises individuals aged 18 years and below [8] and about $50 \%$ of the population is below 15 years [9]. In this study we found that almost half of the students interviewed perceived themselves to be at risk of contracting HIV. Our findings are slightly lower than earlier findings from Kibombo and colleagues who report that among adolescents aged $15-19$ years, $72 \%$ of the females compared to $55 \%$ perceived themselves as being at risk of contracting HIV [6]. The discrepancy between our findings and those reported by Kibombo and colleagues may be explained in several ways. For example, respondents in our study may have underestimated their risk of contracting HIV because of failure to link risk sexual behavior to the likelihood of HIV exposure. Indeed, the lack of behavior change has been signaled as one of the major challenges in the fight against HIV and AIDS in Uganda [2]. This is one of the common problems, reported in other studies as well [10-13]. While in some other studies the tendency to underestimate $\mathrm{HIV}$ risk has been attributed to misconceptions and low knowledge on HIV transmission [14], in Uganda knowledge about HIV transmission and prevention is generally high $[2]$.

\subsection{Factors Associated with Perceived Risk of Contracting HIV.} Results from bivariate analysis indicated that respondents who were male and had ever taken an HIV test had increased odds of perceiving themselves to be at risk of contracting HIV. Other studies also report an association between male gender and HIV risk perception [12]. The most likely explanation for males perceiving themselves to be at risk of contracting $\mathrm{HIV}$ more than females is that males engage in more risky sexual behavior. This behavior raises a suspicion within the individual of a possibility of having been exposed to HIV. Kibombo and colleagues found a highly significant association between perceived risk of contracting HIV and sexual behaviors of male adolescents lending support to the above assertion [6]. In regard to the finding that those who had ever taken an HIV test were more likely to perceive themselves to be at risk of contracting HIV, this should not be surprising because the fear of having been exposed might have been the motive behind seeking testing services. This is in agreement with findings from a study among adolescents in Kenya [15].

Students who knew someone who had died of HIV were more than twice as likely to admit that they were at risk of contracting HIV. This finding remained statistically significant even at the level of multivariable analysis. Similar results were reported by Anderson and others, although the elevated perceived risk was restricted to female respondents [16]. This underscores the point that even though HIV related deaths have been markedly reduced due to widespread availability of antiretroviral drugs, still HIV related death or illness [17] of family member or close relative makes the risk very real to an adolescent and is a powerful modifier of behavior. 
TABLE 2: Factors associated with perceived risk of contracting HIV.

\begin{tabular}{|c|c|c|c|c|c|}
\hline Variable & $\begin{array}{c}\text { Perceive } \\
\text { themselves to be } \\
\text { at risk for HIV } \\
\text { Frequency (\%) }\end{array}$ & $\begin{array}{l}\text { Do not perceive } \\
\text { themselves to be } \\
\text { at risk for HIV } \\
\text { Frequency (\%) }\end{array}$ & COR & $95 \% \mathrm{CI}$ & $P$ value \\
\hline \multicolumn{6}{|l|}{ Gender } \\
\hline Female & $84(42.0)$ & $116(58.0)$ & 0.52 & \multirow{2}{*}{$0.35-0.79$} & \multirow{2}{*}{$0.002^{*}$} \\
\hline Male & $104(58.1)$ & 75 (41.9) & 1.00 & & \\
\hline \multicolumn{6}{|l|}{ Age } \\
\hline$\leq 17$ & $116(44.6)$ & $144(55.4)$ & 1.90 & \multirow{2}{*}{$1.22-2.96$} & \multirow{2}{*}{$0.004^{*}$} \\
\hline$>17$ & $72(60.5)$ & $47(39.5)$ & 1.00 & & \\
\hline \multicolumn{6}{|l|}{ Had HIV test } \\
\hline No & $52(38.8)$ & $82(61.2)$ & 0.51 & \multirow{2}{*}{$0.33-0.78$} & \multirow{2}{*}{$0.002^{*}$} \\
\hline Yes & $136(55.5)$ & $109(44.5)$ & 1.00 & & \\
\hline \multicolumn{6}{|c|}{ Knowledge of HIV status } \\
\hline No & $30(38.8)$ & $19(38.8)$ & 1.31 & \multirow{2}{*}{$0.69-2.49$} & \multirow{2}{*}{0.404} \\
\hline Yes & $107(54.6)$ & $89(45.4)$ & 1.00 & & \\
\hline \multicolumn{6}{|c|}{ Knowledge of a person who died of HIV } \\
\hline Yes & $159(53.7)$ & $137(46.3)$ & 2.16 & \multirow{2}{*}{$1.30-3.58$} & \multirow{2}{*}{$0.002^{*}$} \\
\hline No & $29(34.9)$ & $54(65.1)$ & 1.00 & & \\
\hline \multicolumn{6}{|c|}{ Discussed HIV at home } \\
\hline Yes & $144(51.1)$ & $138(48.9)$ & 1.26 & \multirow{2}{*}{$0.79-1.99$} & \multirow{2}{*}{0.333} \\
\hline No & $44(45.4)$ & $53(54.6)$ & 1.00 & & \\
\hline \multicolumn{6}{|l|}{ Age at sexual debut } \\
\hline $8-14$ years & $61(67.8)$ & $29(32.2)$ & 2.26 & \multirow{2}{*}{$1.22-4.19$} & \multirow{2}{*}{$0.009^{*}$} \\
\hline $15-19$ years & $40(48.2)$ & $43(51.8)$ & 1.00 & & \\
\hline \multicolumn{6}{|l|}{ Has ever had sex } \\
\hline Yes & $101(58.0)$ & $73(42.0)$ & 1.88 & \multirow{2}{*}{$1.25-2.83$} & \multirow[t]{2}{*}{$0.003^{*}$} \\
\hline No & $87(42.4)$ & $118(57.6)$ & 1.00 & & \\
\hline \multicolumn{6}{|c|}{ Had sex in the last 12 months } \\
\hline Yes & $61(59.8)$ & $41(40.2)$ & 0.87 & \multirow{2}{*}{$0.47-1.60$} & \multirow{2}{*}{0.649} \\
\hline No & $40(56.3)$ & $31(43.7)$ & 1.00 & & \\
\hline \multicolumn{6}{|c|}{ Used a condom in the last 12 months } \\
\hline Yes & $28(56.0)$ & $22(44.0)$ & 1.36 & \multirow{2}{*}{$0.62-3.01$} & \multirow{2}{*}{0.443} \\
\hline No & $33(63.5)$ & $19(36.5)$ & 1.00 & & \\
\hline Only one & $44(59.5)$ & $30(40.5)$ & 0.98 & $0.53-1.82$ & 0.946 \\
\hline More than one & $56(59.0)$ & $39(41.0)$ & 1.00 & & \\
\hline
\end{tabular}

Having ever had sex and early sexual debut were all positively associated with perceived risk of contracting HIV. Findings from other studies indicate that individuals who initiate sex early are either noncondom users or use them sporadically [18]. This may be related to inaccessibility of condoms or powerlessness in regard to being able to negotiate for condom use during sexual intercourse. Although the Government of Uganda and other stakeholders have put effort in ensuring availability of condoms and other family planning services in health facilities, adolescents may fail to access these services due to fear of embarrassment as they are not expected to engage in sex. Moreover, these services are not provided in secondary schools in Uganda.
4.3. Sexual Behaviors of the Students. In this study we found that one hundred and seventy-four participants (45.9\%) had ever had sex and about $60 \%$ of these had it within the past twelve months preceding the interview. This finding is much higher compared to $13.4 \%$ reported from the Zambia global school based health survey [19] and in a study conducted in Tanzania among out-of-school adolescents, males were found to significantly more sexually active compared to females [20]. But more importantly in this study slightly above $50 \%$ of the students who had had sex within the twelve months preceding the study reported not to have used a condom. This is a very concerning but not surprising sexual behavior. The Uganda Demographic Health Survey (UDHS) of 2011 
TABLE 3: Sexual behaviors of one hundred and seventy-four students who were sexually active.

\begin{tabular}{lcc}
\hline Variable & Frequency & Percentage (\%) \\
\hline Had sex in the last 12 months $^{*}$ & & \\
$\quad$ Yes & 71 & 59.0 \\
$\quad$ No & & 41.0 \\
Used a condom in the last 12 months & 50 & 49.0 \\
$\quad$ Yes & 52 & 51.0 \\
$\quad$ No & & \\
Number of sexual partners ever had ${ }^{*}$ & 74 & 43.8 \\
$\quad$ One & 95 & 56.2 \\
$\quad$ More than one & & \\
Age at sexual debut & \\
$\quad \leq 16$ & 139 & 80.4 \\
$\quad>16$ & 34 & 19.6 \\
Ever had sex after drinking alcohol & & \\
$\quad$ Yes & 31 & 52.5 \\
$\quad$ No & 28 & 47.5 \\
Ever had sex in exchange for money & & \\
$\quad$ Yes & 34 & 19.8 \\
No & 138 & 80.3 \\
\hline
\end{tabular}

${ }^{*}$ Some missing numbers.

reported that the proportion of individuals who agreed that people can reduce the risk of getting the HIV virus by using condoms every time they have sexual intercourse was lowest among women and men aged 15-19 years [7]. Our findings also indicate that many students were initiating sex before the age of 16 and after drinking alcohol.

4.4. Limitation. Some aspects of the study required participants to recall information about events that happened in the past that may have been difficult for some participants, thus potentially introducing recall bias. To address this problem, we limited the recall period to only twelve months. Also due to the sensitivity of some of the questions asked some respondents may have not told the truth regarding their sexual experiences, introducing misclassification bias. However, during data collection, we emphasized to the respondents the importance of being as honest as possible and the fact that the data would be kept anonymous. We also did not assess students on their knowledge of HIV transmission and maybe this could have been important in understanding their sexual behaviors and practices such as condom use.

4.5. Conclusion. A high proportion of secondary school students perceived themselves to be at risk of contracting HIV and this perception is associated with knowing someone who died of HIV, early sexual debut, and being sexually active. Risk sexual behaviors such as not using condoms, having multiple life time sexual partners, and having sex after drinking alcohol are widespread among secondary school students in Wakiso Town Council. Therefore, there is a need to design and implement targeted school based HIV risk reduction programs.
4.6. Implications for School Health. Findings presented above signify that there may be gaps in current school based HIV prevention interventions in Wakiso Town Council. District health authorities need to develop interventions based upon understanding of HIV risk perception among secondary school students. Since many students reported not to have used condoms even when they engaged in risk sexual behaviors, this may present an opportunity for making condoms widely accessible to students and empowering them to consistently use them. Also, since slightly over fifty percent of the participants engaged in sex at an early age (8-14 years), there is need to initiate HIV risk reduction education programs early in schools.

\section{Appendix}

The questionnaire used for assessing perceived risk of contracting HIV infection and sexual behaviors of secondary school students in Wakiso Town Council, Wakiso district, Uganda, is as follows.

\section{Section A}

(1) What is your age in complete years? ...........

(2) What is your gender?

$$
\begin{aligned}
& 1=\text { Male } \\
& 2=\text { Female }
\end{aligned}
$$

(3) What is your tribe? ................

(4) What is your religion?

$$
\begin{aligned}
& 1=\text { Catholic } \\
& 2=\text { Protestant/Anglican } \\
& 3=\text { Muslim } \\
& 4=\text { Pentecostal } \\
& 5=\text { SDA } \\
& 6=\text { Other, specify ................. }
\end{aligned}
$$

(5) In which class are you?

$$
\begin{aligned}
& 1=\mathrm{S} .3 \\
& 2=\mathrm{S} .4 \\
& 3=\mathrm{S} .6
\end{aligned}
$$

\section{Section B}

(6) Do you perceive yourself to be at risk of contracting HIV?

$$
\begin{aligned}
& 1=\text { Yes } \\
& 2=\text { No }
\end{aligned}
$$

(7) If yes, how do you rate your risk of getting HIV?

$$
\begin{aligned}
& 1=\text { High } \\
& 2=\text { Moderate } \\
& 3=\text { Low }
\end{aligned}
$$


(8) Have you ever taken an HIV test?

$$
\begin{aligned}
& 1=\text { Yes } \\
& 2=\text { No }
\end{aligned}
$$

(9) If yes, do you know your HIV sero status?

$$
\begin{aligned}
& 1=\text { Yes } \\
& 2=\text { No }
\end{aligned}
$$

(10) Do you know anyone who has HIV?

$$
\begin{aligned}
& 1=\text { Yes } \\
& 2=\text { No }
\end{aligned}
$$

(11) If yes, does that make you think you are at risk of contracting HIV?

$$
\begin{aligned}
& 1=\text { Yes } \\
& 2=\text { No }
\end{aligned}
$$

(12) Do you know someone who died of HIV?

$$
\begin{aligned}
& 1=\text { Yes } \\
& 2=\text { No }
\end{aligned}
$$

(13) If yes, does that make you think that you are at risk of contracting HIV?

$$
\begin{aligned}
& 1=\text { Yes } \\
& 2=\text { No }
\end{aligned}
$$

(14) Do you discuss HIV/AIDS at home with parents/guardians?

$$
\begin{aligned}
& 1=\text { Yes } \\
& 2=\text { No }
\end{aligned}
$$

(15) If yes, does this make you think you are at risk of HIV?

$$
\begin{aligned}
& 1=\text { Yes } \\
& 2=\text { No }
\end{aligned}
$$

(16) Have you ever had sexual intercourse?

$$
\begin{aligned}
& 1=\mathrm{No} \\
& 2=\mathrm{Yes}
\end{aligned}
$$

(17) If yes, at what age were you when you had your first sexual encounter?

(18) Have you had sex in the last 12 months?

$$
\begin{aligned}
& 1=\text { Yes } \\
& 2=\text { No }
\end{aligned}
$$

(19) If yes, did you use a condom in your last sexual encounter?

$$
\begin{aligned}
& 1=\text { Yes } \\
& 2=\text { No }
\end{aligned}
$$

(20) Do you drink alcohol?

$$
\begin{aligned}
& 1=\text { Yes } \\
& 2=\text { No }
\end{aligned}
$$

(21) If yes, have you ever had sex when you have taken alcohol?

$$
\begin{aligned}
& 1=\text { Yes } \\
& 2=\text { No }
\end{aligned}
$$

(22) Have you ever engaged in sex in exchange for money/gifts?

$$
\begin{aligned}
& 1=\text { Yes } \\
& 2=\text { No }
\end{aligned}
$$

(23) How many people in total have you ever had sexual intercourse with?

$$
\begin{aligned}
& 1=\text { With one person } \\
& 2=\text { With two people } \\
& 3=\text { More than two }
\end{aligned}
$$

(24) Have you ever had symptoms of Sexually Transmitted Infections, such as genital wound, abnormal genital discharge, pain during urination, or genital swelling?

$$
\begin{aligned}
& 1=\text { Yes } \\
& 2=\text { No }
\end{aligned}
$$

(25) If yes, did you think you were exposed to HIV?

$$
\begin{aligned}
& 1=\text { Yes } \\
& 2=\text { No }
\end{aligned}
$$

\section{Ethical Approval}

Ethical approval for the study was granted by Makerere University School of Health Sciences Institutional Review Board (IRB) under reference no. 006. Permission was sought from Wakiso district authorities and from the head teachers of the selected schools. Verbal assent and informed consent was sought from each individual participant before being involved in the study. Each student was informed of his or her right to withdraw from the study at any time without fear of negative consequences. The participants of the study were treated as mature minors as per the guidelines for research involving human subjects as stipulated by the Uganda National Council of Science and Technology.

\section{Competing Interests}

The authors declare that they have no competing interests. 


\section{Authors' Contributions}

Charles Peter Osingada, Caroline Nabasirye, and Tom Denis Ngabirano were responsible for the study conception and design. Charles Peter Osingada and Caroline Nabasirye were responsible for the data collection and analysis. Charles Peter Osingada and Caroline Nabasirye were responsible for data interpretation and drafting of the paper. Charles Peter Osingada, Caroline Nabasirye, Tom Denis Ngabirano, and Sara Groves made critical revisions to the paper for important intellectual content. All authors read and approved the final paper.

\section{Acknowledgments}

The authors acknowledge all the students who participated in this study and the district and school authorities for the support rendered during the conduct of the study.

\section{References}

[1] UNAIDS, UNAIDS Global Epidemic Report, UNAIDS, 2013.

[2] Ministry of Health, Uganda AIDS Indicator Survey (UAIS), 2011.

[3] E. Y. Tenkorang, E. Maticka-Tyndale, and F. Rajulton, "A multilevel analysis of risk perception, poverty and sexual risk-taking among young people in Cape Town, South Africa," Health \& Place, vol. 17, no. 2, pp. 525-535, 2011.

[4] J. F. Kengeya-Kayondo, L. M. Carpenter, P. M. Kintu, J. Nabaitu, R. Pool, and J. A. G. Whitworth, "Risk perception and HIV-1 prevalence in 15,000 adults in rural south-west Uganda," AIDS, vol. 13, no. 16, pp. 2295-2302, 1999.

[5] J. A. Cederbaum, T. D. Gilreath, and A. Barman-Adhikari, "Perceived risk and condom use among adolescents in subSaharan Africa: a latent class analysis," African journal of reproductive health, vol. 18, no. 4, pp. 26-33, 2014.

[6] R. Kibombo, S. Neema, and F. H. Ahmed, "Perceptions of risk to HIV infection among adolescents in Uganda: are they related to sexual behaviour?" African Journal of Reproductive Health, vol. 11, no. 3, pp. 168-181, 2007.

[7] UBOS, Uganda Demographic and Health Survey (UDHS), Uganda Bureau of Statistics, 2011.

[8] Uganda Bureau of Statistics (UBOS), The state of Uganda population report 2012.

[9] UBOS, The State of Uganda Population Report, UBOS, 2013.

[10] K. T. Ijadunola, T. C. Abiona, O. O. Odu, and M. Y. Ijadunola, "College students in Nigeria underestimate their risk of contracting HIV/AIDS infection," European Journal of Contraception and Reproductive Health Care, vol. 12, no. 2, pp. 131-137, 2007.

[11] F. Samkange-Zeeb, S. Pöttgen, and H. Zeeb, "Higher risk perception of HIV than of chlamydia and HPV among secondary school students in two German cities," PLoS ONE, vol. 8, no. 4, Article ID e61636, 2013.

[12] V. Sychareun, S. Thomsen, K. Chaleunvong, and E. Faxelid, "Risk perceptions of STIs/HIV and sexual risk behaviours among sexually experienced adolescents in the Northern part of Lao PDR," BMC Public Health, vol. 13, no. 1, article 1126, 2013.

[13] E. S. Maswanya, K. Moji, T. Yamamoto, K. Aoyagi, Y. Yahata, and T.-I. Takemoto, "Sexual behavior and condom use among male students in Dar-Es-Salaam, Tanzania with emphasis on contact with barmaids," East African Journal of Public Health, vol. 9, no. 1, pp. 39-43, 2012.

[14] L. M. Bogart and S. Thorburn, "Are HIV/AIDS conspiracy beliefs a barrier to HIV prevention among African Americans?" Journal of Acquired Immune Deficiency Syndromes, vol. 38, no. 2, pp. 213-218, 2005.

[15] E. Y. Tenkorang and E. Maticka-Tyndale, "Individual- and school-level correlates of HIV testing among secondary school students in Kenya," Studies in Family Planning, vol. 44, no. 2, pp. 169-187, 2013.

[16] K. G. Anderson, A. M. Beutel, and B. Maughan-Brown, "HIV risk perceptions and first sexual intercourse among youth in Cape Town, South Africa," International Family Planning Perspectives, vol. 33, no. 3, pp. 98-105, 2007.

[17] K. Macintyre, N. Rutenberg, L. Brown, and A. Karim, "Understanding perceptions of HIV risk among adolescents in KwaZulu-Natal," AIDS and Behavior, vol. 8, no. 3, pp. 237-250, 2004.

[18] C. W. Kabiru and P. Orpinas, "Correlates of condom use among male high school students in Nairobi, Kenya," Journal of School Health, vol. 79, no. 9, pp. 425-432, 2009.

[19] S. Siziya, A. S. Muula, L. N. Kazembe, and E. Rudatsikira, "Harmful lifestyles' clustering among sexually active in-school adolescents in Zambia," BMC Pediatrics, vol. 8, article 6, 2008.

[20] K. S. Mnyika, M. C. Masatu, and K.-I. Klepp, "Perceptions of AIDS risk and condom use among out-of-school adolescents in Moshi rural district, northern Tanzania," East African Journal of Public Health, vol. 9, no. 2, pp. 53-57, 2012. 


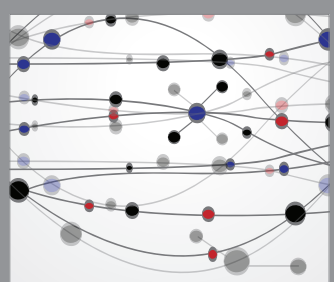

The Scientific World Journal
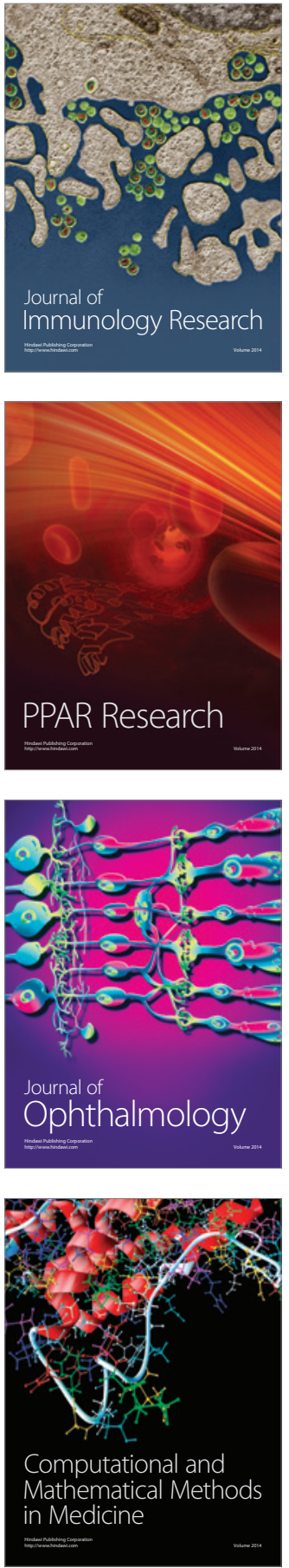

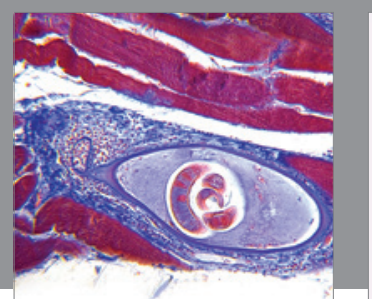

Gastroenterology Research and Practice

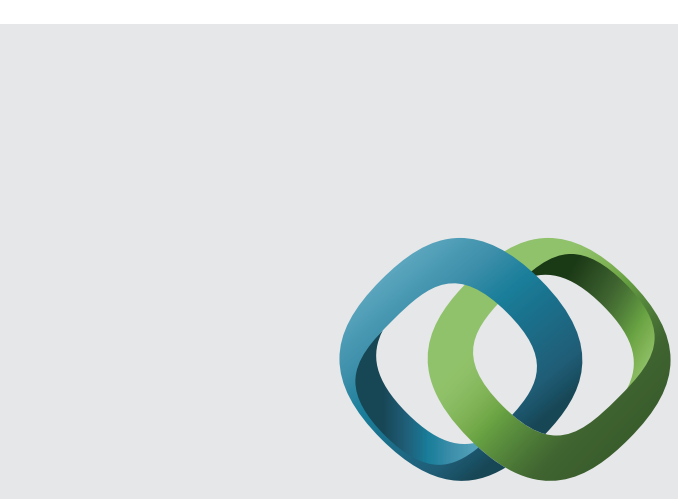

\section{Hindawi}

Submit your manuscripts at

http://www.hindawi.com
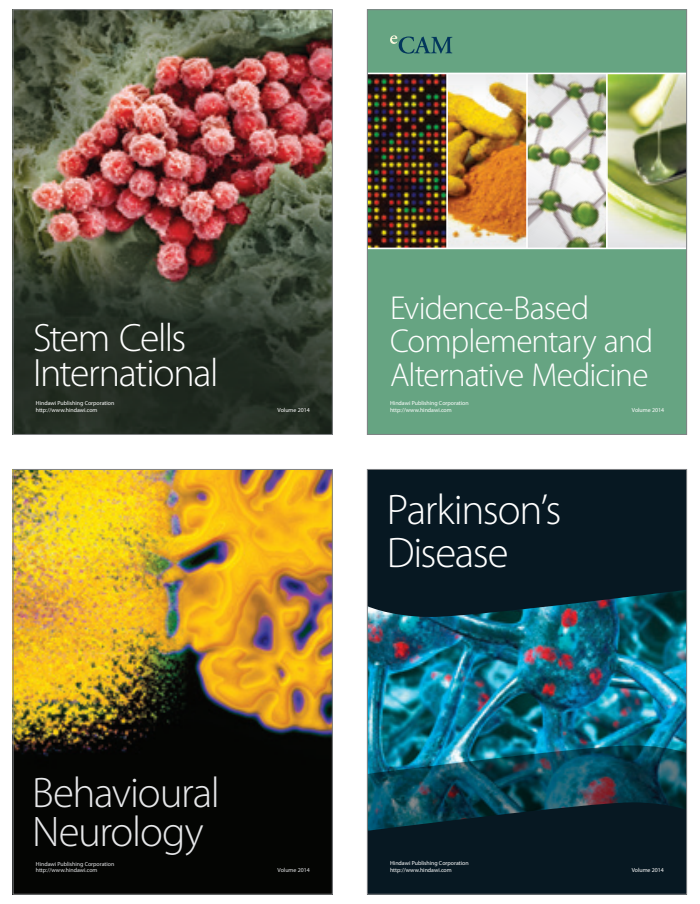
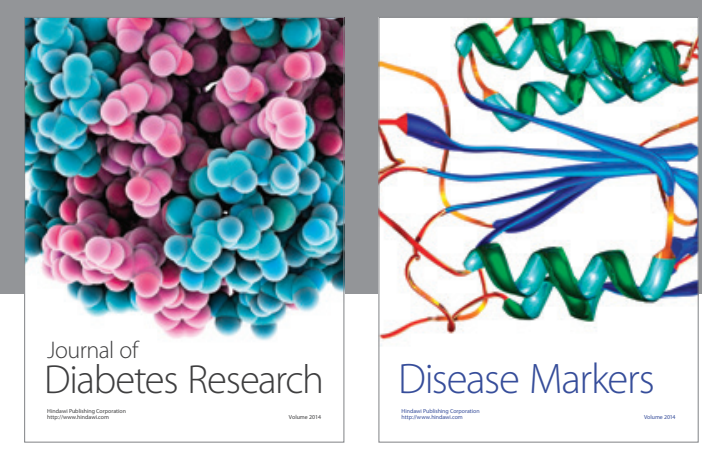

Disease Markers
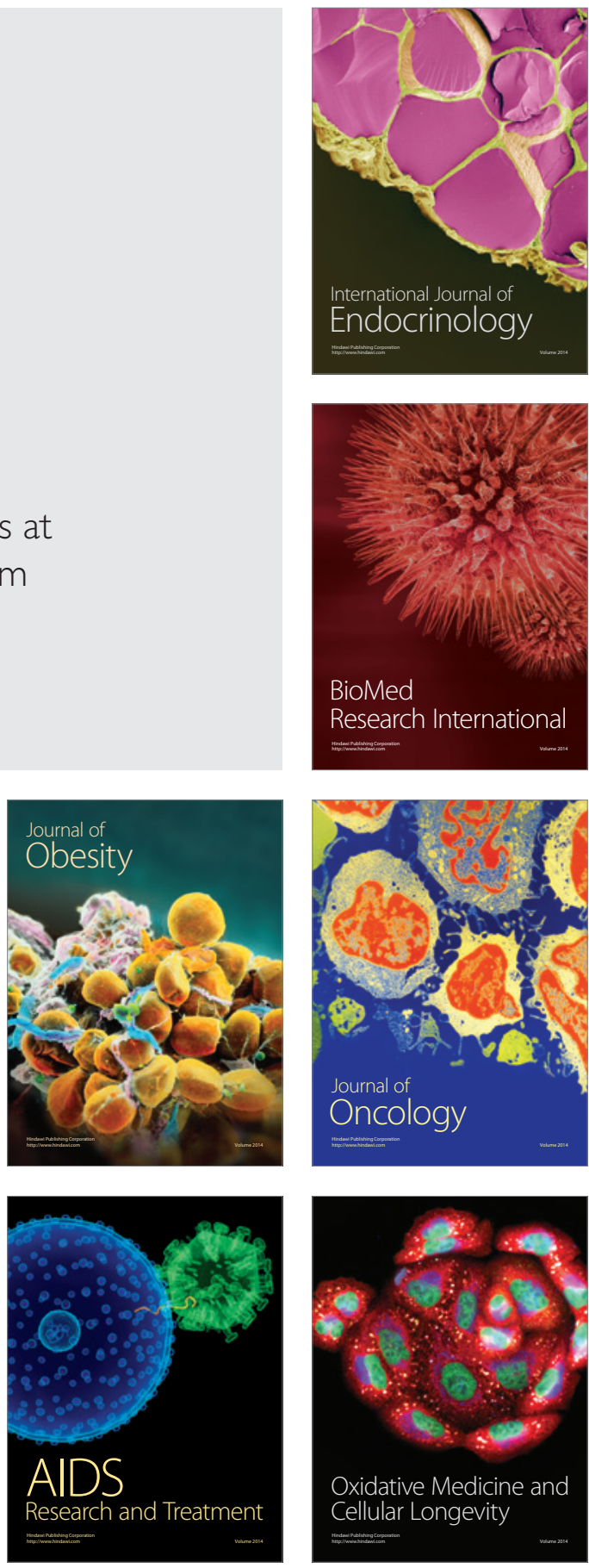